\title{
RANCANG BANGUN DIES BATAKO UNTUK PEMBUATAN 10 BATAKO DALAM SEKALI PROSES
}

\author{
Syafiqul Arif \\ Fakultas Teknik, Program Studi Teknik Mesin \\ Universitas Muria Kudus \\ Email: mesin@umk.ac.id \\ Qomaruddin \\ Fakultas Teknik, Program Studi Teknik Mesin \\ Universitas Muria Kudus \\ Email: qomaruddin@umk.ac.id \\ Rochmad Winarso \\ Fakultas Teknik, Program Studi Teknik Mesin \\ Universitas Muria Kudus \\ Email: rochmad.winarso@umk.ac.id
}

\begin{abstract}
ABSTRAK
Perkembangan ilmu pengetahuan dan teknologi telah mengalami peningkatan yang sangat pesat. Keadaan ini berimbas pada semua bidang kehidupan manusia salah satunya adalah bidang produksi batako. Selama ini pembuatan batako dibuat dengan cara manual belum dapat menghasilkan efisiensi waktu yang cepat. Salah pencapaian efisiensi waktu tersebut dengan desain dies yang lebih tepat dalam pencapaian jumlah hasil produksi. Dari hasil survey yang dilakukan, pengerjaan pembuatan batako secara manual masih belum dapat menghasilkan waktu yang efisien. Karena produk dengan kapsitas rendah dan kualitas belum standar batako seperti yang ada dipasaran. Dari permasalahan perlu adanya inovasi yang mendukung proses produksi yang lebih baik. Tujuan yang akan dicapai adalah merancang bangun dies untuk sebuah cetakan pengepresan batako dengan kapasitas 10 batako dalam sekali proses. Metode yang akan dilakukan adalah tinjauan pustaka, merancang dies, perhitungan, proses manufaktur, analisa simulasi pembebanan manual dan simulasi inventor. Hasil penelitian adalah rancang bangun dies untuk mengepres batako yang dapat menghasilkan 10 balok dalam sekali cetak.
\end{abstract}

\section{Kata kunci: Batako, Dies, Mesin Press}

\begin{abstract}
The development of science and technology has increased very rapidly. This situation has an impact on all areas of human life, one of which is the production of concrete blocks. So far the making of concrete blocks made manually has not been able to produce fast time efficiency. Incorrect achievement of time efficiency with a dies design that is more precise in achieving the amount of production. From the results of the survey conducted, the construction of manual brick making still cannot produce an efficient time. Because products with low capacity and quality are not standard brick blocks like those on the market. From the problem there needs to be innovation that supports a better production process. The goal that will be achieved is to design a dies for a mold pressing brick with a capacity of 10 blocks in a single process. The method that will be done is a literature review, designing dies, calculations, manufacturing processes, analysis of manual loading and inventor simulation. The result was the design of the dies to press concrete blocks that can produce 10 beams in one print.
\end{abstract}

Keywords: Brick making, Dies, Press Machine 


\section{PENDAHULUAN}

Batako adalah campuran antara semen, agregat, dan air dengan atau tanpa bahan tambahan. Batako yang dihasilkan oleh industri kecil pada umumnya adalah batako padat. Batako tersebut dilihat secara langsung menunjukkan kualitas yang cukup baik dengan permukaan yang mulus. Dari hasil peninjauan di lapangan menunjukkan adanya perbedaan hasil yang dicapai antara industri kecil dan industri rumah tangga dalam hal jumlah batako yang dihasilkan dalam satu zak semen. Batako yang dihasilkan oleh industri kecil bervariasi antara 90-120 buah sedangkan pada industri rumah tangga bervariasi antara 60-80 buah batako. Dengan adanya perbedaan jumlah batako yang dihasilkan dalam satu zat semen akan memberikan perbedaan kuat tekan yang mana jumlah batako yang dihasilkan lebih banyak memiliki nilai kuat tekan yang lebih kecil dibandingkan jumlah batako yang dihasilkan lebih sedikit. Hal seperti ini menunjukkan bahwa dalam pembuatan batako masih berdasarkan pengalaman yang tidak memperhatikan karakteristik dari batako seperti gradasi agregat, berat jenis, kadar air, kuat tekan, dan proporsi campuran batako [1].

Proses cetak batako yang dibuat dengan mesin cetak yang otomatis menghasilkan produk menjadi lebih berkualitas, karena ukuran seragam, bentuk batako presisi, permukaan lebih rata, daya serap bahan lebih bagus, pori-pori batako lebih rapat. Waktu produk juga menjadi lebih cepat dan efisien sehingga nilai ekonomis produk menjadi lebih tinggi [2]. Prinsip-prinsip arsitektur moderen ada pada batako beton manual seperti pemakaian bahan dan peralatan kerja ekonomis serta cara pembuatan efektif dan efisien. Proses pembuatan batako beton manual cenderung sulit memenuhi permintaan jumlah batako yang tinggi karena tenaga pekerja terbatas [3]. Dengan demikian penting untuk diteliti perbandingan antara batako manual dan mekanik terhadap alat-alat kerja, bahan-bahan, dan cara membuat agar diketahui efektifitas, efisiensi, dan keekonomisan [4].

Pembuatan dies batako ini bertujuan untuk mempercepat produksi dan meringankan pekerja karena mesin press yang akan di buat ini mampu menghasilkan 10 buah batako dalam sekali pengepressan. Dalam proses pembuatan dies pemilihan material sangatlah penting agar dies kuat dan tidak berubah bentuk dan produk yang akan dihasilkan memenuhi standar yang ada di pasaran. Selain pemilihan material yang tepat, desain dies juga berpengaruh pada masa umur pakai dies. Desain dies yang salah dapat mengakibatkan beberapa kerugian pada saat dies sudah digunakan untuk proses produksi. Salah satu kendala yang sering ditemui dilapangan adalah penyetingan dies yang banyak memakan waktu, masalah ini timbul karena kesalahan saat pertama kali pembuatan desain dies. Cara mengatasi permasalahan ini adalah dengan mendesain ulang kontruksi dies dengan mempertimbangkan permasalahan-permasalahan yang timbul pada desain dies sebelumnya [5]]

Hasil yang diharapkan dalam pembuatan progressive dies ini adalah agar proses produksi dilakukan secara efisien dan dengan tingkat kepresisian yang tinggi.

\section{METODOLOGI PENELITIAN}

Penelitian ini dilakukan melalui tiga tahapan yaitu: (1) Tahap perancangan atau desain dies (2) Tahap pembuatan dies dengan ukuran maupun dimensi yang sudah ditentukan (3) Tahap pengujian tahap pengujian sendiri menggunakan metode autodesk inventor 2015.

Pada pengujian menggunakan beban $0,16 \mathrm{Mpa}$, sedangkan pengujian menggunakan pembebanan tekanan (pressure). Bentuk dies seperti di tunjukkan pada gambar 1. 


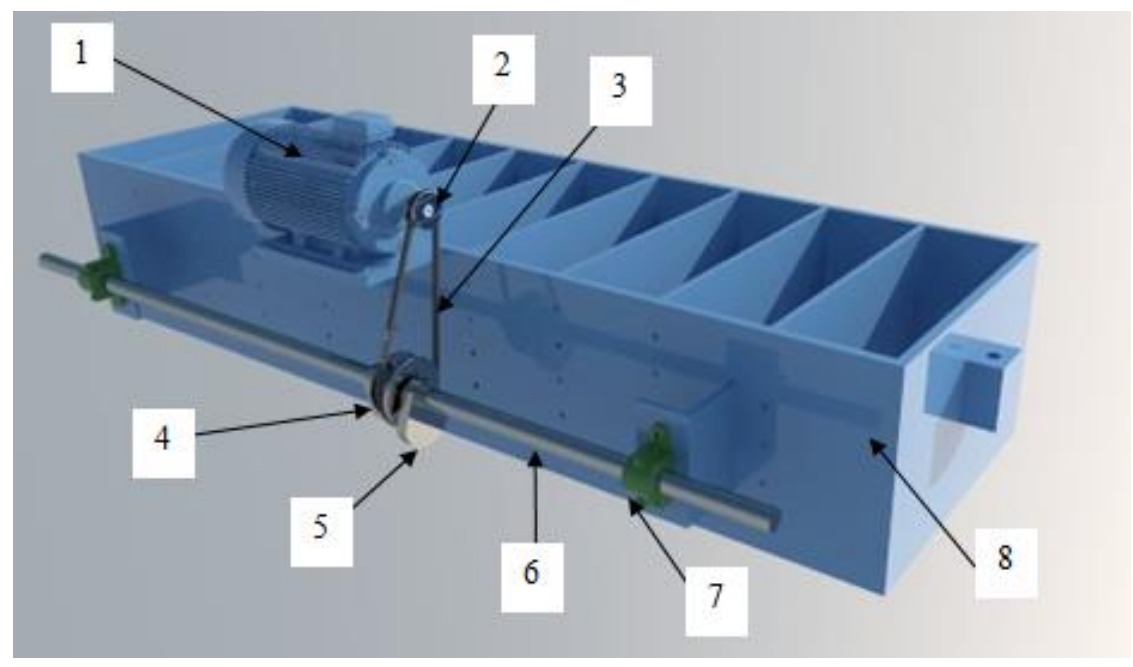

Gambar 1, skema hasil perakitan dies

Keterangan :

1. Motor Penggerak

2. Pulli 1

3. V-belt

4. Pulli 2

5. Bandul

6. Poros

7. Bearing

8. Cetakan

\section{HASIL DAN PEMBAHASAN}

\subsection{Pengujian menggunakan metode software autodesk inventor}

Pengujian dilakukan untuk mengetahui berapa besar tegangan (stress), regangan (strain), perpindahan (displacement) pembebanan preassure dilakukan pada dinding-dinding plat dies atau ruang pengepressan batako, ruang batako terbagi menjadi 10 bagian yang mempunyai ukuran yang sama. Simulasi pengujian terdapat 22 titik yang terkena tekanan akibat gaya pengepresan. 


\subsection{Hasil simulasi}

Tabel 1, nilai pembebanan pressure

\begin{tabular}{|l|ll|}
\hline $\begin{array}{l}\text { Name } \\
\text { Volume }\end{array}$ & $\begin{array}{l}\text { Minimum } \\
12240000 \mathrm{~mm}^{\wedge} 3\end{array}$ & Maximum \\
\hline Mass & $96,084 \mathrm{~kg}$ & \\
\hline Von Mises Stress & $0,000310186 \mathrm{MPa}$ & $0,0188562 \mathrm{MPa}$ \\
\hline 1st Principal Stress & $-0,00779006 \mathrm{MPa}$ & $0,00432057 \mathrm{MPa}$ \\
\hline $\begin{array}{l}\text { 3rd Principal Stress } \\
\text { Displacement }\end{array}$ & $-0,0257465 \mathrm{MPa}$ & $0,000609048 \mathrm{MPa}$ \\
\hline Safety Factor & $15 \mathrm{ml}$ & $0,000000920098 \mathrm{~mm}$ \\
\hline Stress XX & $-0,0222474 \mathrm{MPa}$ & $0,000942524 \mathrm{MPa}$ \\
\hline
\end{tabular}

\begin{tabular}{|l|l|l|}
\hline Stress XY & $-0,00553585 \mathrm{MPa}$ & $0,00576002 \mathrm{MPa}$ \\
\hline Stress XZ & $-0,0075195 \mathrm{MPa}$ & $0,00751958 \mathrm{MPa}$ \\
\hline Stress YY & $-0,0222239 \mathrm{MPa}$ & $0,00280504 \mathrm{MPa}$ \\
\hline Stress YZ & $-0,0077305 \mathrm{MPa}$ & $0,00773651 \mathrm{MPa}$ \\
\hline Stress ZZ & $-0,0095346 \mathrm{MPa}$ & $0,00234986 \mathrm{MPa}$ \\
\hline X Displacement & $-0,000000774397 \mathrm{~mm}$ & $0,000000774274 \mathrm{~mm}$ \\
Y Displacement & $-0,000000781099 \mathrm{~mm}$ & $0,000000781102 \mathrm{~mm}$ \\
\hline Z Displacement & $-0,000000497011 \mathrm{~mm}$ & $0,000000463728 \mathrm{~mm}$ \\
\hline Equivalent Strain & $0,00000000128671 \mathrm{ul}$ & $0,0000000844639 \mathrm{ul}$ \\
\hline 1st Principal Strain & $-0,000000000983707 \mathrm{ul}$ & $0,0000000318566 \mathrm{ul}$ \\
\hline 3rd Principal Strain & $-0,000000100916 \mathrm{ul}$ & $-0,000000000363981 \mathrm{ul}$ \\
\hline Strain XX & $-0,0000000786983 \mathrm{ul}$ & $0,00000000885812 \mathrm{ul}$ \\
\hline Strain XY & $-0,0000000342696 \mathrm{ul}$ & $0,0000000356572 \mathrm{ul}$ \\
\hline Strain XZ & $-0,0000000465493 \mathrm{ul}$ & $0,0000000465498 \mathrm{ul}$ \\
\hline Strain YY & $-0,0000000894108 \mathrm{ul}$ & $0,0000000122806 \mathrm{ul}$ \\
\hline Strain YZ & $-0,0000000478555 \mathrm{ul}$ & $0,0000000478927 \mathrm{ul}$ \\
\hline Strain ZZ & $-0,00000000197188 \mathrm{ul}$ & $0,0000000318552 \mathrm{ul}$ \\
\hline
\end{tabular}

Hasil dari simulasi pembebanan pressure

Dari analisa pengujian didapat von mises stress maksimal sebesar 0,0188562 Mpa, seperti yang di tunjukkan pada gambar 2 . 


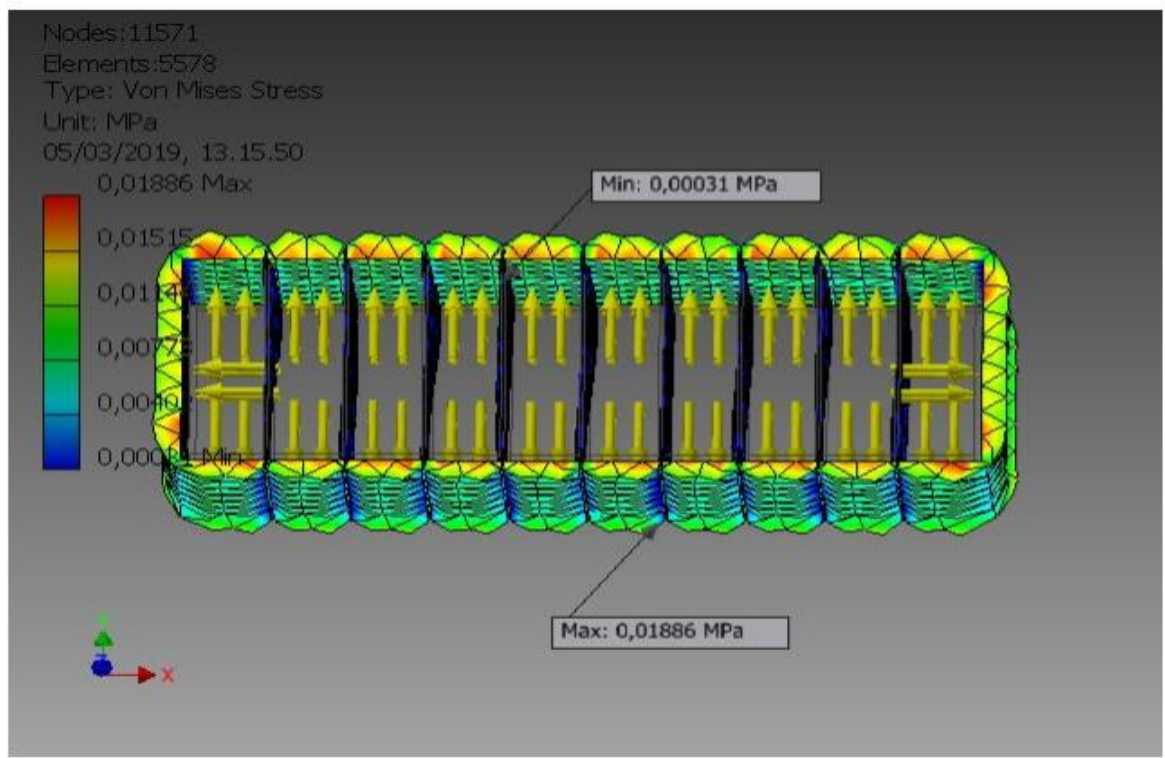

Gambar 2, Hasil analisa pengujian von mises stress

Dari analisa pengujian didapat perpindahan (displacement) maksimal dari arah vektor Y sebesar $0,000000463728 \mathrm{~mm}$, seperti di tunjukkan pada gambar 3 .

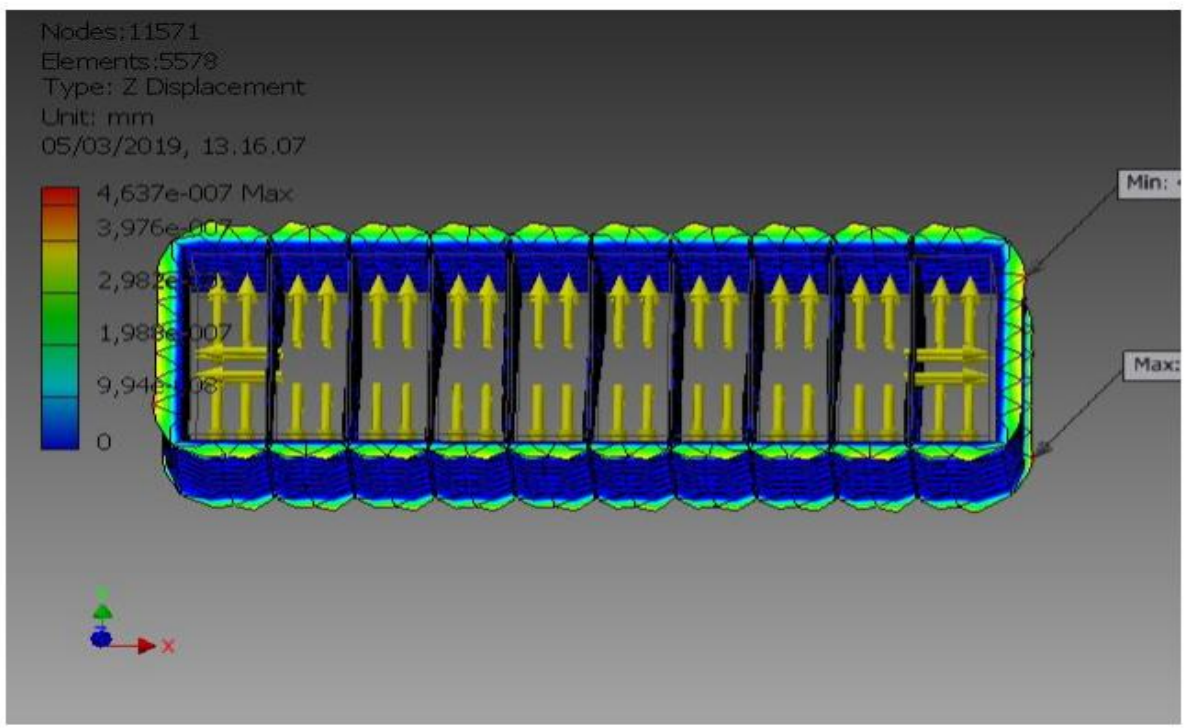

Gambar 3, Hasil analisa pengujian perpindahan (displacement)

Hasil simulasi menunjukkan bahwa tegangan yang terjasi akibat gaya pengepresan sebesar 1,336 Mpa. Regangan normal terjasi pada penampang dies sebagai akibat dari gay pengepresan sebesar 0,00000638 ul. Nilai displacement yang terjadi pada penampang dies akibat gaya pengepresan sebesar 0,004265 . Secara keseluruhan nilai hasil simulasi memenuhi syrat disain dies. 


\section{KESIMPULAN}

1. Maka tegangan (stress) yang terjadi pada dies akibat gaya pengepresan sebesar 1,366 Mpa.

2. Maka regangan normal yang terjadi pada penampang dies akibat gaya pengepresan sebesar 0,00000638 ul.

3. Maka displacement perpindahan yang terjadi pada penampang dies akibat gaya pengepresan sebesar $0,004265 \mathrm{~mm}$.

\section{DAFTAR PUSTAKA}

[1] Annisa Mulia Rani St.Mt, Analisis Kapasitas Produksi Plant 3 Pada Mesin Turbo Mix, Teknik Industri.

[2] Utomo, T., \& Susanto, B. 2009, Otomatisasi Alat Cetak Bahan Bangunan (Batako dan Paving Block) Pada Industri Rakyat Yang Berbasiskan Sumber Daya Lokal. Jurnal Mitra Akademika, Volume XIII-Maret.

[3] Umar, M., Z. 2016, Prinsip-prinsip Arsitektur Moderen Pada Pembuatan Batako PC Yang Dikerjakan Secara Manual Di Kota Kendari. Proceeding SNTT4 Inovasi Lanjut Dalam Teknik dan Sains Terapan. FGDT-PTM VII Universitas Muhammadiyah Purwokerto 26 November.

[4] Agustinus Purna Irawan. 2009. Diktat elemen mesin. Universitas Tarumanagara

[5] Ersan Wijayanto, 2012, Analisa Kekuatan Rangka Mesin Press Batako Styrofoam Dan Press Botol Plastik, Teknik Mesin, digilib.uns.ac.id 